\title{
ORAL FEEDING BEHAVIOUR FOLLOWING CONGENITAL DIAPHRAGMATIC HERNIA
} REPAIR

\author{
J. Dhaliwal ${ }^{1}$, G. Feint ${ }^{2}$, P. Belani ${ }^{1}$, C. Jackson ${ }^{1}$, V. Murthy ${ }^{1}$, A. Hickey ${ }^{1}$ \\ ${ }^{I}$ Department of Child Health, ${ }^{2}$ Speech and Language Therapy, Kings College Hospital NHS Foundation \\ Trust, London, UK
}

Background and aims: Feeding difficulties and nutritional compromise are recognised sequelae in survivors following congenital diaphragmatic hernia $(\mathrm{CDH})$ repair. This study aims to investigate factors which may influence oral feeding behaviour in this complex group.

Methods: Data analysis on 35 survivors of $61 \mathrm{CDH}$ patients between 2007 and 2010.

Results: 16 (46\%) of 35 patients had oral feeding problems (OFP) and had a speech and language therapy (SALT) assessment. ( table 1)

$6(38 \%)$ of those required a gastrostomy.

Ventilator days for patients with oral aversion was 26.5 versus 19 days in those without $(\mathrm{P}<0.01)$. (table 2)

21 patients had had antenatal fetal endoscopic tracheal occlusion (FETO) of whom 11(52\%) had OFP.

$12(75 \%)$ of the OFP group had a patch repair versus $10(53 \%)$ in the non OFP group.

\begin{tabular}{|l|l|l|l|l|}
\hline Gastrostomy & $\begin{array}{l}\text { Oro-facial } \\
\text { Hypersensitivity }\end{array}$ & Oral Aversion & Food Refusal & Disorganised Suck \\
\hline No $(\mathrm{n}=10)$ & 0 & 0 & 0 & $10(100 \%)$ \\
\hline Yes $(\mathrm{n}=6)$ & $5 / 6(83 \%)$ & $5 / 6(83 \%)$ & $5 / 6(83 \%)$ & $6 / 6(100 \%)$ \\
\hline
\end{tabular}

[Table 1 SALT Assessment ]

\begin{tabular}{|c|c|c|c|c|c|c|}
\hline Gastrostomy & $\begin{array}{l}\text { Gestation at } \\
\text { birth }\end{array}$ & Birth centile & FETO & Patch repair & $\begin{array}{l}\text { Ventilator } \\
\text { days }\end{array}$ & $\begin{array}{l}\text { Weight centile } \\
\text { at discharge }\end{array}$ \\
\hline No $(n=10)$ & $37(35-41)$ & $25 \operatorname{th}(0.4-75)$ & $7 / 10(70 \%)$ & $7 / 10(70 \%)$ & $15(12-47)$ & 2nd (0.4-25) \\
\hline Yes $(n=6)$ & $34(33-38)$ & 25 th $(2-75)$ & $4 / 6(67 \%)$ & $5 / 6(83 \%)$ & $22(6-55)$ & 0.4 th $(0.4-2)$ \\
\hline
\end{tabular}

[Table 2 Abnormal feeding behaviour group]

Conclusion: In our study, almost half of the survivors had OFP, particularly those with a prolonged ventilatory course. Many required long term input in specialist feeding clinics. This information is important for counselling and suggests that early SALT and nutritional assessment and intervention are essential. 